\title{
A Study of Bubble Structures in Porcelain Enamel ${ }^{*}$
}

\author{
By Yoshio NAKAZATO, ,* Hideo KUGUMINATO, ,* Naohiko SOEDA** \\ and Isao TAKAHASHI***
}

\begin{abstract}
Synopsis
Through an investigation into the effect of bubble structures in a ground coat on the quality of enameled products, it was found that an increase in bubble sizes tends to cause chipping and reduces impact resistance of the products. But no conclusion was reached as to the effect of an increased bubble size on adhesion properties since the test results are not consistent with the types of measuring methods. Further study of factors governing bubble structures revealed that bubbles occur at the boundaries of frit particles, and that small frit particles make small bubbles. Bubbles grow bigger as the heat supply is increased during firing before they rise to the surface and disperse into the air.

It was also found that a hard type frit with a high fusion point makes smaller bubbles than a soft type frit does, and that the bubbles size can be controlled by changing the combination of frits mixed in a slip. Also, the bubble size changes with the amount of clay and silica used as mill additions.
\end{abstract}

\section{Introduction}

Porcelain enamel, when sprayed and fired on a steel surface, contains numerous pores and holes, and so called bubble structures. These gas bubbles in enamels are formed during the firing of an enameling ware. ${ }^{1)}$ The gas originates from 1) carbon and hydrogen in the base steel, 2) combined or adsorped water in the frit, 3) water and organic materials in the clay and the mill additions, and 4) water vapor in the atmosphere in the firing furnace.

There have been several reports concerned with the quality of enameled products due to the effects of bubble structures. For example, the bubbles which are important in inhibiting fishscales are those which are contained in an approximately 0.001 inch thick enamel layer adjacent to the interface. ${ }^{2,3)}$ When a transparent glaze is used for the cover coat, transparency and gloss are reduced by the increase in the volume of the bubbles. ${ }^{4}$ )

In the production of an enameled ware, there are some problems such as chipping, poor impact resistance and poor adhesion which may be affected by bubble structures. The purpose of this investigation is to evaluate the effects of bubble structures on these problems. Also, the study of the factors governing bubble structures is discussed.

\section{Influence of Bubble Structures on Defects in Enameled Wares}

\section{Chipping}

With an enameled ware, it is most important to prevent the enamel from fracturing in order to im- prove its quality. There are two types of fractures; cracking and chipping. Cracking is caused by strong external impact and by an excessively thick coating. Chipping is the flaking off of enamel pieces during cooling or later by internal stress or a soft impact.

The internal stress in the enamel layer can be explained as follows. Enamels have a lower thermal expansion coefficient than steels, so the enamel layer is compressed after firing. Enamels have a higher resistance against compression than that against tension and a suitable compressive stress makes enamel strong, but an immoderate compressive stress results in chipping. In view of these points, the thermal expansion coefficient of an enamel must be balanced with that of a base steel. Care on this point has reduced the rate of chipping.

A bent or welded porcelain enameled panel, however, has sharp corners. Chipping is commonly found on the welded corners. It originates from a cavity or hair crack in the welded metal. Its prevention depends upon the welding technique.

The corners bent at $90^{\circ}, 70^{\circ}$ or $45^{\circ}$ were two-coat enameled. Figure 1 shows the effects of bend angles and bubble structures on chipping. Chipping is likely to occur at sharp corners and also is more likely to occur with large bubbles than small ones because of the concentration of residual stresses and the weakening of the enamels.

Photograph 1 shows bubble structures; comparing the chipping layer with the normal. There are large bubbles in the ground coat under the chipping. We

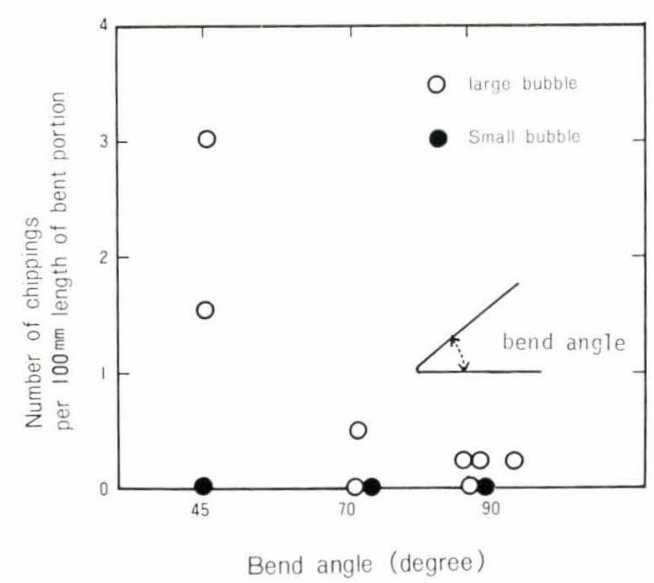

Fig. 1. Relation between chipping on bend angle and bubble size in gound coat.

* Originally published in Kawasaki Steel Technical Report, 9 (1977), 167, in Japanese. English version received February 5, 1979.

** Chiba Works, Kawasaki Steel Corp., Kawasaki-cho, Chiba 260.

*** Research Laboratories, Kawasaki Steel Corp., Kawasaki-cho, Chiba 260. 
found that large bubbles visible to the naked eye often remain under the chipped enamel.

In conclusion, enameling has to be controlled to form bubble structures with homogeneously distributed small bubbles and the thermal expansion coefficient of an enamel must be optimized to prevent chipping.

\section{Impact Resistance}

External impacts crack the porcelain enamel layer. Impact resistance depends on the shape of the products, the strength of the base steel, the adherence of the enamel to a steel, the residual stress in the enamel layer and so on.

It has been shown ${ }^{5)}$ that an increase in the thickness of the enamel and/or metal and an increase in the radius result in increased impact resistance. Impact resistance increases with the reduction of an thermal expansion coefficient of the ground coat but

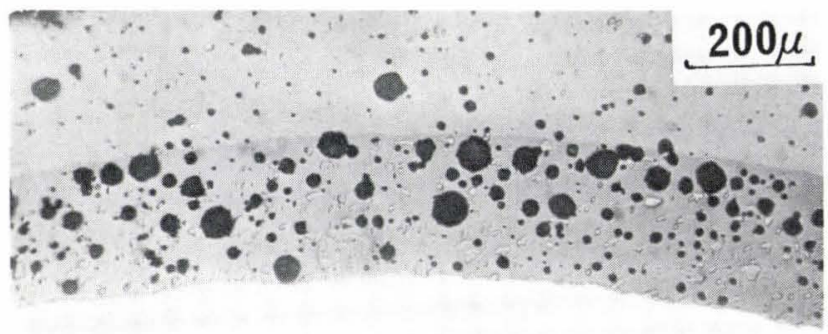

Normal

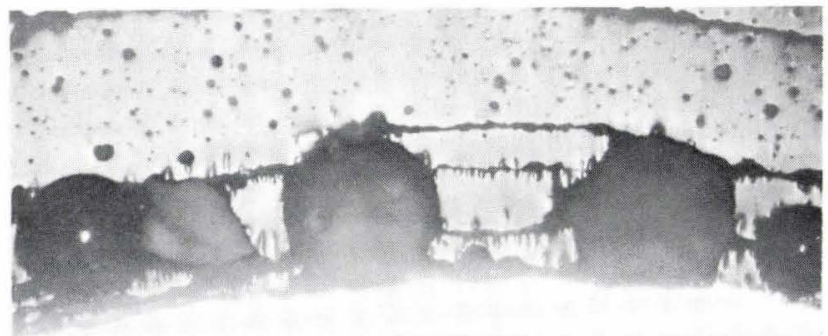

Chipping

Photo. 1. Bubble structures in the cross section of enamel layer. not with that of the cover coat. The shape of the products and the thickness of the base steel can not be changed because of their design limitations. So we must study how to strengthen porcelain enamel to increase the impact resistance of the products.

The relation between impact resistance and bubble structures was investigated. Photograph 2 shows the dependence of bubble sizes and the thickness of the enamel on impact resistance. The results of the falling weight test (JIS A 5532) are shown in Fig. 2. After dropping a steel ball from a specific height, we judged the results on the following four grades;

1) Fracture: enamel is cracked.

2) Dimple with an internal crack: impact point, about $1 \mathrm{~mm}$ in diameter; swelling because of an internal crack.

3) Unusual responsive sound: surface is undeformed or has a little dimple, tapping the impact point produces an unusual sound indicating an internal crack.

4) Normal: enamel does not change.

The solid line in Fig. 2 represents the "fracture limit "; the maximum height of the falling ball without causing fracture. The broken line is the " internal crack limit" for the grades between 2) and 3). An increase in the thickness of the enamel results in an increased impact resistance as reported by Andrews ${ }^{6)}$ but the limits depend on the kind of ground coat; the impact strength of ground coat B is higher than that of ground coat A. The difference of the two ground coats is tabulated in Table 1. It is clear that the difference in impact resistance comes from the bubble structures; namely, impact resistance decreases as the occupation ratio of large bubbles more than $40 \mu \mathrm{m}$ in diameter increases. This size has no special physical meaning but was determined for conveniences' sake from the experience.

\section{P.E.I. Adherence Index}

Many studies of adherence between an enamel and a base steel have been discussed. The mechanism of adherence can be explained by mechanical and chemi-
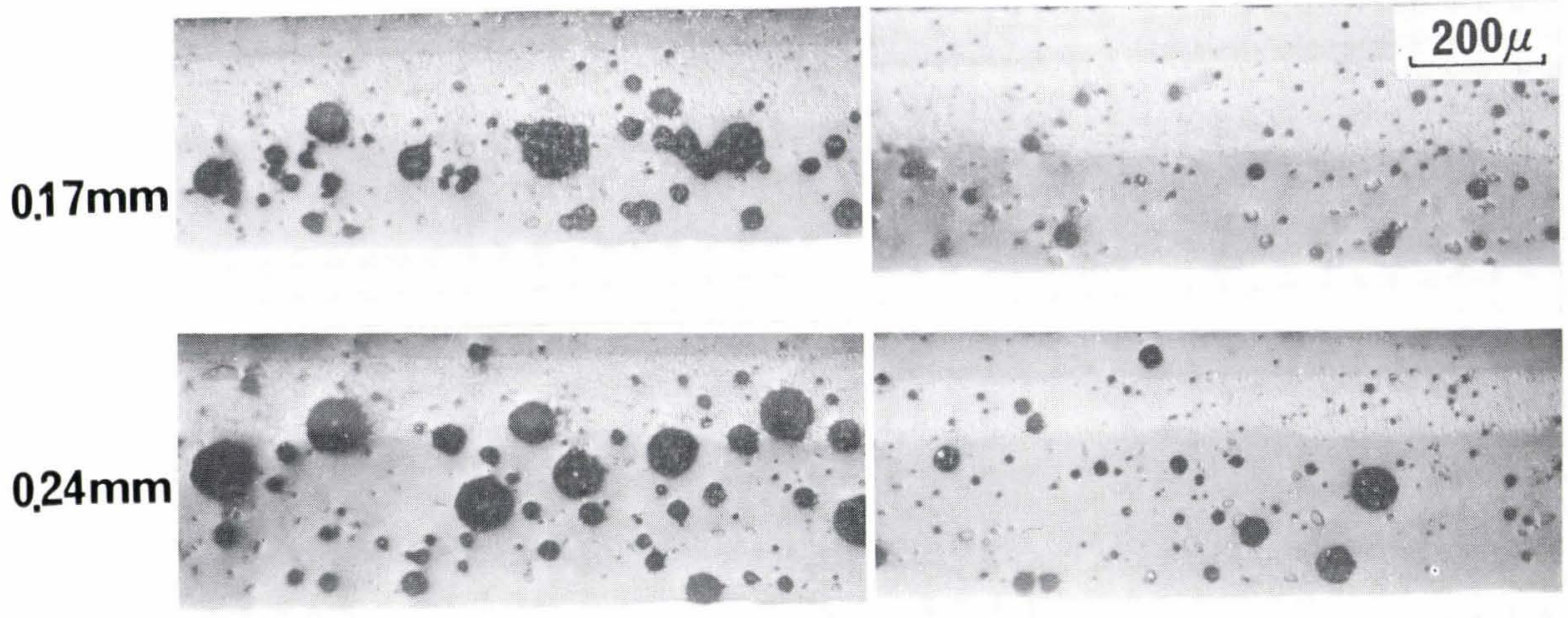

Ground coat A

Photo. 2. Bubble srtuctures in the cross section of impact test specimens.
Ground coat B 


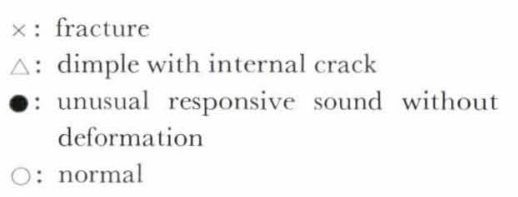

Fig. 2. Influence of total enamel thickness on impact resistance.

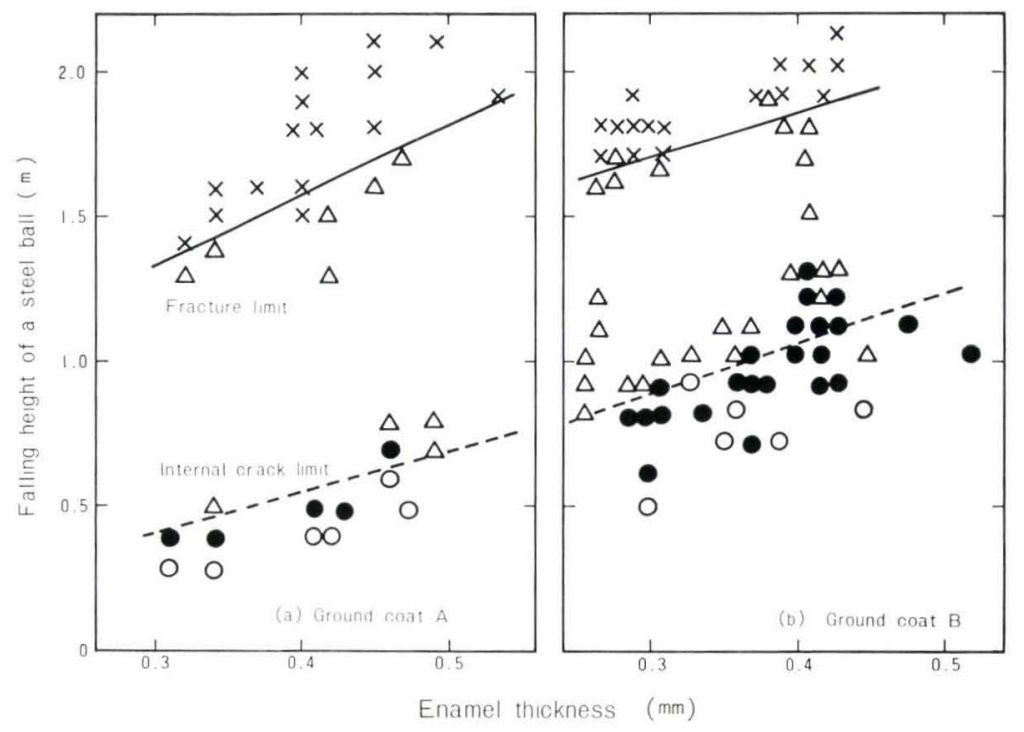

Table 1. Effect of enamel thickness and of bubble size in ground coat on impact resistance.

\begin{tabular}{|c|c|c|c|c|c|}
\hline \multirow{2}{*}{\multicolumn{2}{|c|}{$\begin{array}{c}\text { Type of ground coat slip } \\
\text { Enamel thickness }(\mathrm{mm})\end{array}$}} & \multicolumn{2}{|c|}{ A } & \multicolumn{2}{|c|}{$\mathrm{B}$} \\
\hline & & 0.30 & 0.50 & 0.30 & 0.50 \\
\hline Ground coat thickness & $(\mathrm{mm})$ & 0.17 & 0.24 & 0.17 & 0.24 \\
\hline $\begin{array}{l}\text { Occupation ratio of lars } \\
\text { bubbles }\end{array}$ & ge $(\%)$ & 8.2 & 17.2 & 0 & 2.5 \\
\hline Internal crack limit & $(\mathrm{mm})$ & 400 & 700 & 900 & 1200 \\
\hline Fracture limit & $(\mathrm{mm})$ & 1300 & 1800 & 1700 & 2000 \\
\hline
\end{tabular}

cal bonding. ${ }^{1)}$ The former is thought to be the result of keying the enamel to a roughened base steel and the latter is the reactions that occur at the interface between the two components. The adherence depends on the chemical components of the enamel, base steel, pretreatment and firing condition.

The measurement of adherence strength is a further problem. Falling weight test and P.E.I. adherence test ${ }^{7}$ ) were carried out for this study. The results of the falling weight test are summarized in Table 1. The influences of the bubble structures and pickling iron loss on P.E.I. index are shown in Fig. 3. Pickling iron loss affects P.E.I. index, as previously reported. ${ }^{8,9)}$

Large bubbles seem to improve P.E.I. index and these results are the opposite of those of the falling weight test. Depending on the bubbles, the surfaces after press deformation, however, are very different. The specimen with small bubbles and enough pickling loss has the same P.E.I. index as that of large bubbles with poor pickling loss. In the case of small bubbles, the dispersed residual ground coat looks like a concentric circle on the surface. In the case of large bubbles, a base steel appears on the surface after deformation. This is because large bubbles interrupt the crack propagation, and then portions of the enamel remain on the steel even if the adherence is poor, resulting in a higher P.E.I. index. Therefore, the bubble structure has to be taken into consideration to evaluate the adherence using the P.E.I. index.

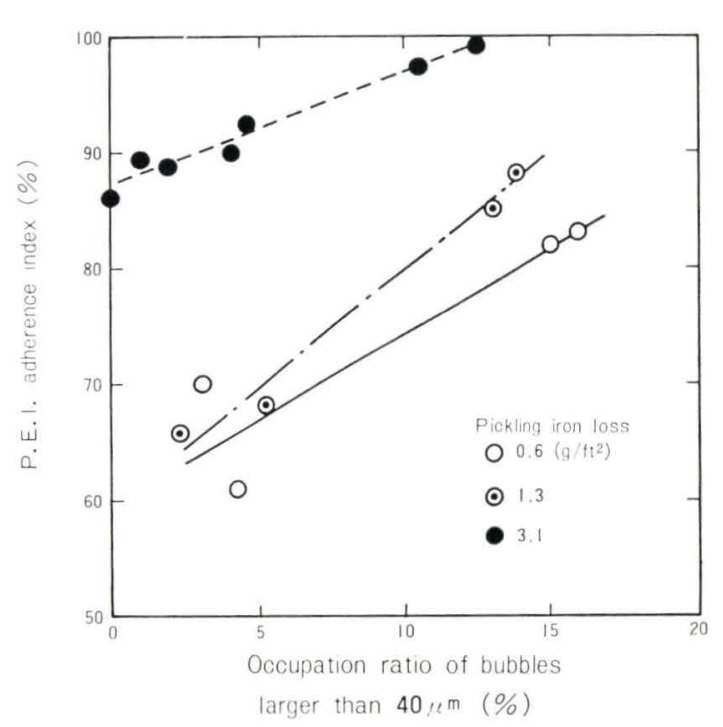

Fig. 3. Influences of pickling iron loss and large bubbles in ground coat on P.E.I. adherence index.

\section{Effect of Frit on Bubble Structures}

Bubble structures in a ground coat have much influence on the quality of porcelain enamel. Thus the effect of frits is examined first.

\section{Frit Size}

Frit is ground to a desired size by a ball mill. To examine the exact influence of frit size, the test procedure was carefully selected as is shown below.

(1) Wet grinding is popular in enameling on steel, but dry grinding without water and mill additions was adopted in this examination.

(2) Humidity and atmosphere in the firing furnace have some influence, so the test specimens were fired in an electric furnace.

(3) Base plates were preliminary fired at a high temperature $\left(850^{\circ} \mathrm{C}\right.$ ) with $\mathrm{Ti}$ white enamel to reduce the effect of gases from the base steel.

The ground coat frit was screened into two grades; large particles $(0.42 \sim 0.125 \mathrm{~mm}$ in diameter $)$ and small ones (smaller than $0.043 \mathrm{~mm}$ in diameter). 


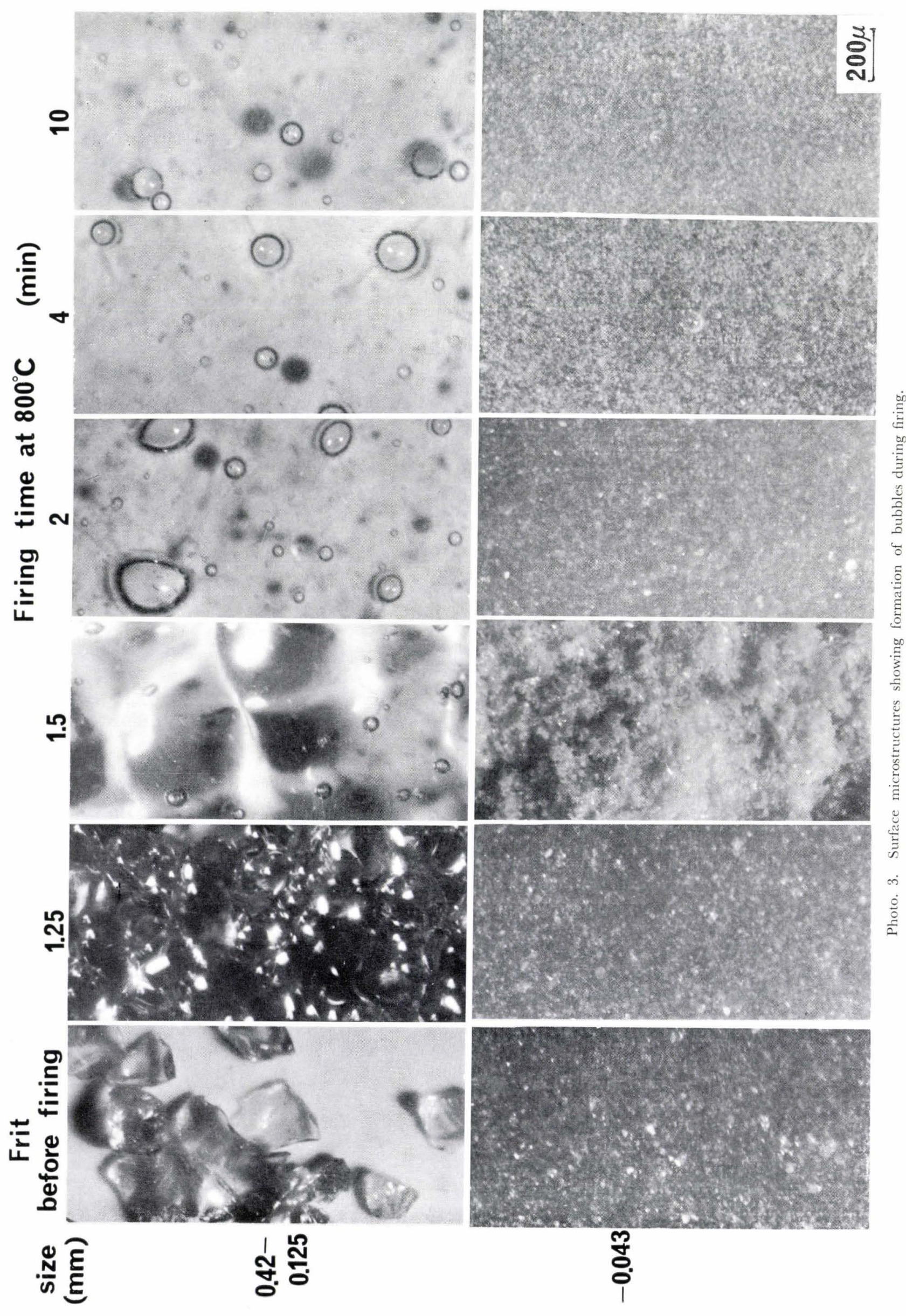


The two dry frits were coated on the Ti white enameled plates and fired at $800^{\circ} \mathrm{C}$ for a particular time. Photograph 3 shows the formation process of the bubbles. The change in the size and number of the bubbles during firing are shown in Fig. 4.

These phenomena could be described as follows: in the case of large frit particles, the sharp edges of a particle melt first after a $1.25 \mathrm{~min}$ firing, changing from an angular particle to a globular one, and then the particles adhere together, but no bubble appears. At $1.5 \mathrm{~min}$, irregular bubbles about $50 \mu \mathrm{m}$ in diameter are recognized among unmelted frit particles and many cavities remain as shown in Photo. 4. At 2 min, large irregular and regular bubbles coexisted. The shape of the irregular bubbles indicates that these bubbles originated from the cavities. Further firing makes all the bubbles globular and enlarge up to about $200 \mu \mathrm{m}$ in diameter. No bubble with a diameter of $200 \mu \mathrm{m}$ is found and the size after 10 min firing is at most $100 \mu \mathrm{m}$ in diameter.

In the case of small frit particles, on the other hand, small bubbles with diameter of $5 \mu \mathrm{m}$ almost cover the entire surface and begin to enlarge gradually at 1.5 min. Even after $10 \mathrm{~min}$ firing, the average bubble size is $30 \mu \mathrm{m}$ in diameter.

The size of the frit particles affects both the size and number of the bubbles. The number of fine bubbles originated from small frit particles is 50 times more than that from large frit ones. It suggests that the air in cavities between unmelted frit particles

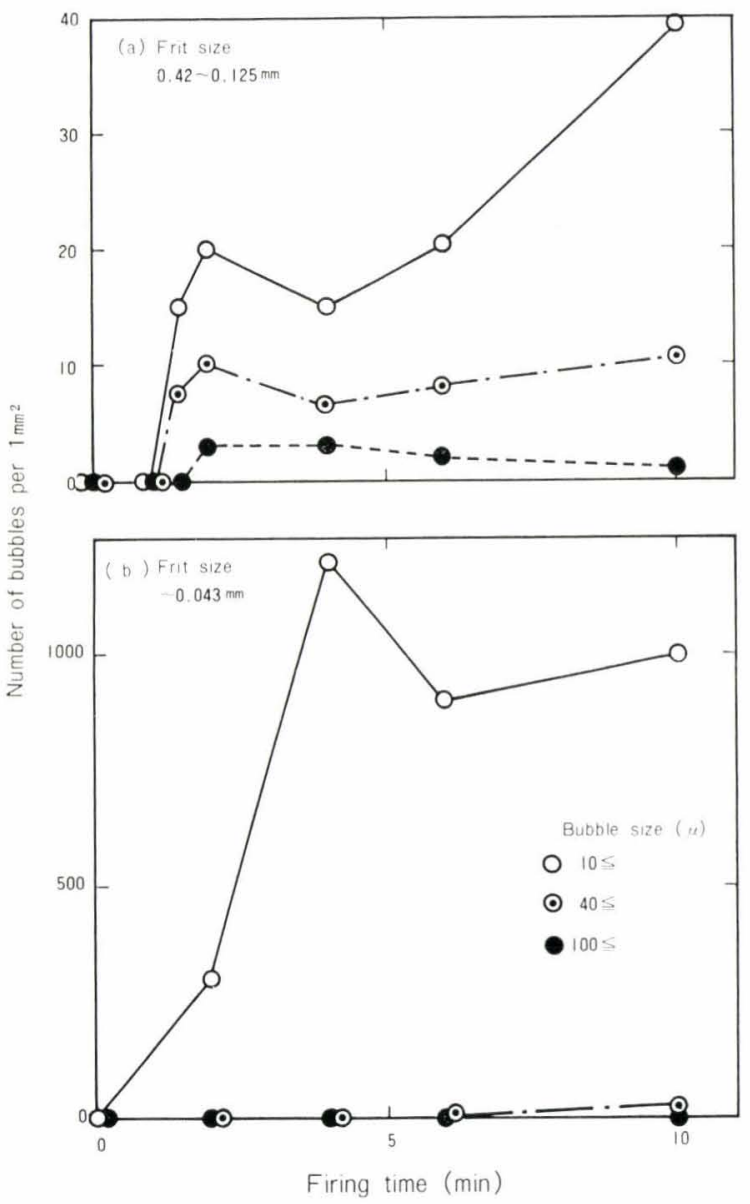

Fig. 4. Change in bubble size with firing time at $800^{\circ} \mathrm{C}$. yields bubbles. At the initial stage of the firing, the surface is fused and gaseous products are entrapped in the enamel. Continued firing results in the expansion of the gas. As the fusion of the enamel proceeds, bubble structures are formed. At the final stage, some bubbles rise to the surface of the enamel and burst into the atmosphere because of low viscosity of the enamel.

\section{Frit Constituent}

Generally the quality of a cover coat is improved by using a frit with a high constituent ratio of $\mathrm{SiO}_{2}$ or $\mathrm{TiO}_{2}$ that has a high melting point and requires a high firing temperature. However, the firing temperature of a ground coat should be higher than that of a cover coat because the bubbles in the ground coat float up to the cover coat layer and make pinhole defects during the cover coat firing. On the other hand, the firing temperature is limited by the transformation temperature of a base steel. The firing above the transformation temperature results in a large sag value and promotes hydrogen adsorption which is detrimental to fishscaling.

It is evident, on considering these factors, that the firing temperature of a ground coat should be lower than the transformation temperature and be $20^{\circ} \sim$ $40^{\circ} \mathrm{C}$ higher than the expected firing temperature of a cover coat. Since this range is not so wide, the selection of frit constituents of the ground coat is important.

Most ground coat enamels are usually mixed with three or more types of frits; hard, middle and soft types. Hard type means the frit with a high melting point and high viscosity. The soft type melts at a low temperature and covers the surface of a base steel, protecting it from over oxidation. The middle type is a binder of different kinds of frits. The mixing ratio of the frits is designed in the limitation of the cover coat quality having small bubble structures as described previously.

In order to find a desirable mixing ratio, the properties of one-frit ground coat must be clear before the effects of frit mixing can be understood.

\section{One-frit Ground Coat}

Frits with designated firing temperatures of $900^{\circ}$,

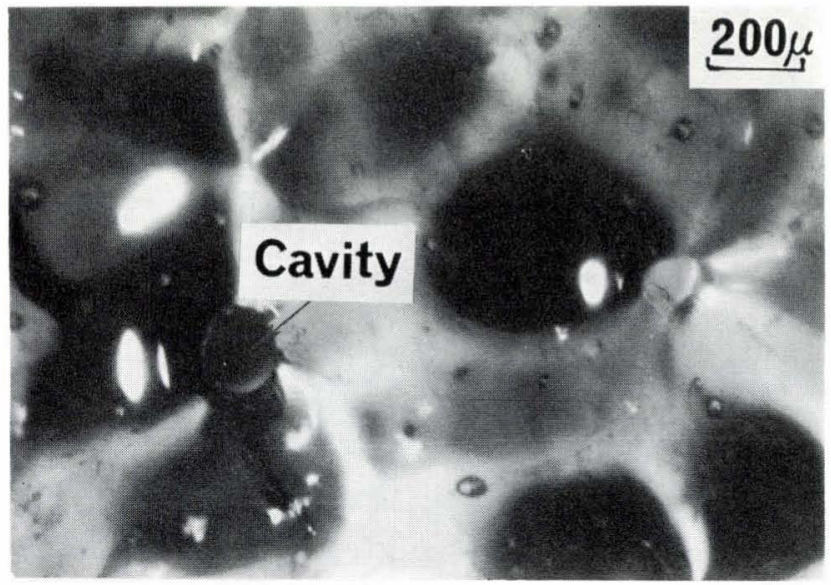

Photo. 4. Microstructure showing cavities after 1.5 min firing. 
$860^{\circ}, 800^{\circ}$ and $760^{\circ} \mathrm{C}$, are used for this test and fired at $900^{\circ}, 860^{\circ}$ and $800^{\circ} \mathrm{C}$ for $6 \mathrm{~min}$. The sizes of the frit particles are controlled to be smaller than 0.043 $\mathrm{mm}$ in diameter, because the frit size after an ordinary milling operation is so small in size; $85 \%$ of the frit particles become less than $0.043 \mathrm{~mm}$ and the size affects the bubble structures as described before.

The type of frit is estimated by the fusion flow index (FFI). The fusion flow indices of these frits are 26, 33, 52 or $53 \mathrm{~mm}$ corresponding with designated temperatures of $900^{\circ}, 860^{\circ}, 800^{\circ}$ or $760^{\circ} \mathrm{C}$. The higher the designated temperature is, the lower FFI is because of its melting point and viscosity. It means FFI is one of the reasonable estimations for the property of a frit.

Figure 5 shows the relations between FFI and average bubble sizes. Bubble sizes are measured by observing the surfaces with a microscope. When FFI is low, the bubble size is small. Low FFI means the high viscosity at the firing temperature, so the bubbles cannot grow. At a high temperature, the surface of frit particles melts easily, then the air in cavities between unmelted particles is entrapped.

In conclusion, small bubbles are obtained by using small frit particles with low FFI and by firing at a low temperature. The minimum suitable size of the frit particles is decided by the strength of the dried enamel before firing. The lowest limit of the firing temperature depends on the type of cover coat.

\section{Multiple-frit Ground Coat}

The influence of the constituents of the ground coat on bubble structures is tested using two kinds of the slip as shown in Table 2. Hard and soft type slips in Table 2 are only different on frit constituents and the frit size is equal. The cover coat is conventional white enamel containing $\mathrm{TiO}_{2}$. A base steel is decarburized for the enamel use. The materials are pretreated, sprayed and dried under conventional conditions. Firing temperatures of the ground coat are selected at four levels; $780^{\circ}, 820^{\circ}, 860^{\circ}$ and $880^{\circ} \mathrm{C}$ and the cover coat refired at $800^{\circ} \mathrm{C}$. Firing speed is $1.9 \mathrm{~m} / \mathrm{min}$ and soaking time is $4 \mathrm{~min}$ in a conventional tunnel furnace.

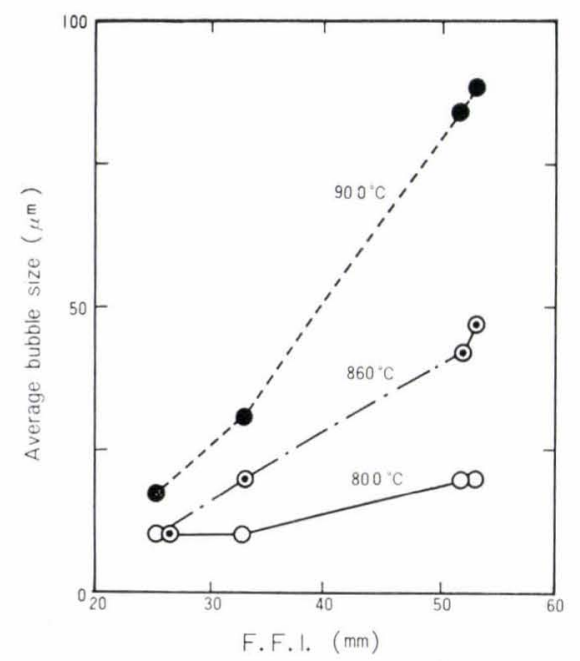

Fig. 5. Relations between fusion flow index (FFI) of frit and average bubble size after firing.
Bubble structures cannot be seen from the surface but can in a cross section of the enamel layer. The total area of bubbles larger than $40 \mu \mathrm{m}$ in diameter is described as an occupation ratio in the ground coat. Even in this evaluation, the occupation ratio of a number of large bubbles is higher than that of many small bubbles.

Figure 6 depicts the relation between occupation ratios and firing temperatures. At $820^{\circ} \mathrm{C}$ firing the occupation ratio in hard type slip is $1 / 10$ of that in soft type or less. In the case of hard type slip, the

Table 2. Constituent and F.F.I. of ground coat slip.

\begin{tabular}{|c|c|c|c|c|c|}
\hline & & & & $\begin{array}{l}\text { Hard } \\
\text { type } \\
\text { slip }\end{array}$ & $\begin{array}{l}\text { Soft } \\
\text { type } \\
\text { slip }\end{array}$ \\
\hline \multirow{6}{*}{$\begin{array}{l}\text { Con- } \\
\text { stituent }\end{array}$} & \multirow{5}{*}{ Frit } & No. & $\begin{array}{l}\text { Standard firing } \\
\text { temp. }\left({ }^{\circ} \mathrm{C}\right)\end{array}$ & \multirow{5}{*}{$\begin{array}{l}30(\%) \\
45\end{array}$} & \multirow{3}{*}{$20(\%)$} \\
\hline & & 1 & 860 & & \\
\hline & & 2 & 840 & & \\
\hline & & 3 & 770 & & 30 \\
\hline & & 4 & 750 & & 50 \\
\hline & $\begin{array}{c}\text { Mill } \\
\text { additions }\end{array}$ & \multicolumn{2}{|r|}{$\begin{array}{l}\text { Clay } 1 \\
\text { Silica } \\
\text { Borax } \\
\mathrm{NaNO}_{2} \\
\mathrm{H}_{2} \mathrm{O}\end{array}$} & $\begin{array}{l}5(\%) \\
5 \\
0.3 \\
0.1 \\
40\end{array}$ & $\begin{array}{l}\text { Same as } \\
\text { in hard } \\
\text { type }\end{array}$ \\
\hline \multicolumn{4}{|c|}{ F.F.I. of slip } & 35 & 43 \\
\hline
\end{tabular}

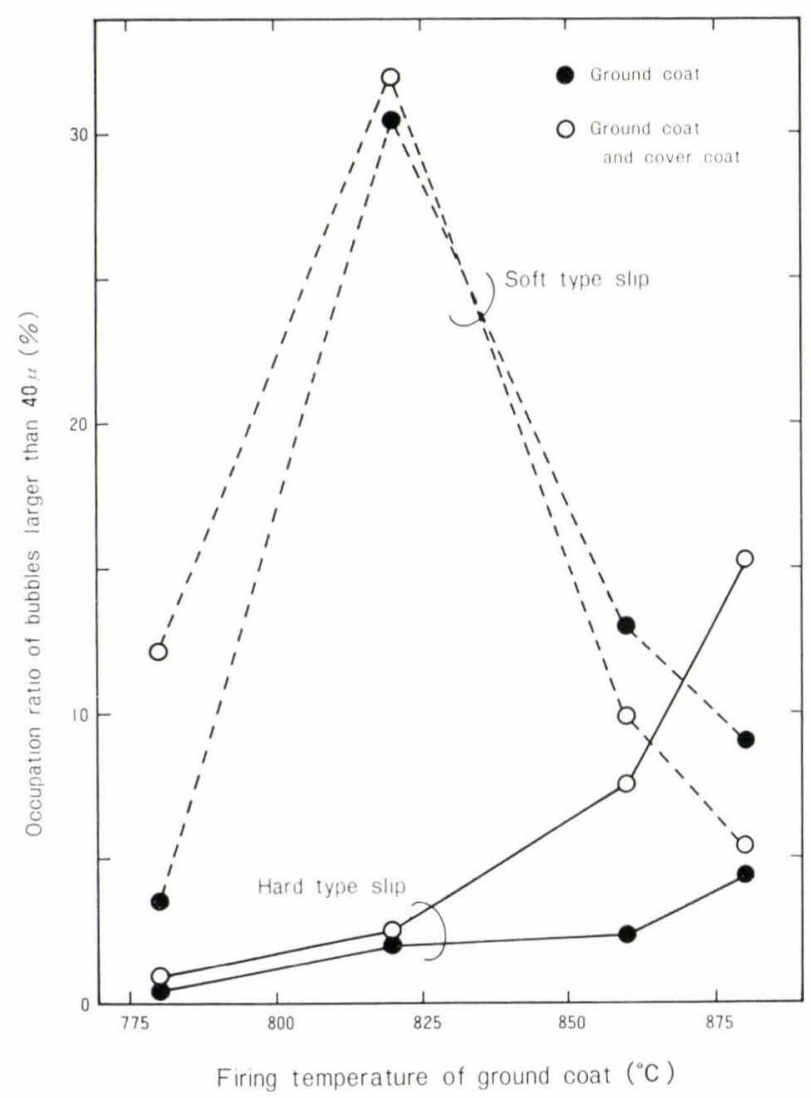

Fig. 6. Influences of firing condition and type of slip on occupation ratio of bubbles in ground coat larger than $40 \mu \mathrm{m}$ in diameter. 
higher the firing temperature is, the larger the occupation ratio is. After cover coat firing, the occupation ratio increases further.

In the case of soft type slip, the occupation ratio increases as the firing temperature increases up to $820^{\circ} \mathrm{C}$. It decreases, however, after firing at temperature higher than $820^{\circ} \mathrm{C}$. It suggests that the bubbles may flow out during the high temperature firing. The occupation ratios of hard and soft type are nearly the same when firing at $860^{\circ} \mathrm{C}$ but overfiring of soft type slip is risky because of poor adherence and copperhead due to the growth of ferrooxides.

First of all, the firing temperature of a cover coat is decided by its quality, then that of a ground coat is decided to be higher than the cover coat. The optimum constituents of a ground coat frit should be selected to form small bubble structures at this temperature.

\section{Effects of Mill Additions on Bubble Struc- tures}

Clay, silica and vehicle are called mill additions. Clay is the most common floating agent, makes the frit colloidal and also makes dried slip hard. Main components of clay are $\mathrm{SiO}_{2}$ and $\mathrm{Al}_{2} \mathrm{O}_{3}$, thus its melting point is high. Bubbles also come from carbon in the organisms contained in clay. Therefore clay is added to control bubble structures of the fired enamel.

Silica is of course a main component of frit and has a high melting point, but it is also used for controlling the properties of the slip as a mill addition because it protects the enamel from thinning during firing. In this meaning, silica makes the suitable firing temperature range wide. Effective bubbles for resisting fishscale is increased by silica addition. ${ }^{3)}$

The vehicle is generally an electrolyte and used for controlling the properties of the slip. Since enamel slips contain colloidal materials, such as clay, small particles and other fine grained mill additions, they are quite sensitive to these electrolytes. But the electrolytes are also a source of gases. The following is the results obtained by the mill addition of clay and silica which influence bubble structures.

\section{Clay}

The three types of slips are supplied for this test. The slips differ in the clay's brand and quantity. Slips are sprayed on the decarburized steel sheets, dried and fired in a tunnel furnace at $860^{\circ} \mathrm{C}$ for 4 min. The bubble structures are evaluated at a cross section of the enamel layer.

Table 3 shows that the fusion flow indices of the three slips are the same. The kinds and the amount of the clay, however, have a large influence on the occupation ratio of large bubbles. Even if the melting point of the slips is not changed by clay addition, clay gives rise to various bubble structures. Therefore, the effects of organisms contained in the clay are most influential in determining bubble structures as reported before. ${ }^{10)}$

\section{Silica}

Three types of slips are prepared based on No. II type in Table 3 . The contents of silica as mill addition are varied from 5, 10 to $15 \%$ of the frit. Increase in the contents of silica decreases FFI to 36, 35 or $33 \mathrm{~mm}$. Three slips are sprayed on the decarburized steel, dried and fired at $860^{\circ} \mathrm{C}$ for $4 \mathrm{~min}$. Then cover coats are fired twice at $820^{\circ} \mathrm{C}$ for $4 \mathrm{~min}$. Bubbles are estimated not only in the ground coat but also in the middle coat as shown in Fig. 7.

Increase in silica reduces the occupation ratio of the bubbles, especially in the middle coat. Small bubbles are dispersed homogeneously in the ground coat and the number of effective bubbles which are located near the base steel increases. In another view, unmelted silica interrupts the growth of small bubbles. Silica addition gives rise to small bubbles

Table 3. Effect of clay on bubble structure.

\begin{tabular}{|c|c|c|c|c|c|c|}
\hline & & & & I & II & III \\
\hline & & No. & $\begin{array}{l}\text { Standard } \\
\text { firing temp. } \\
\left({ }^{\circ} \mathrm{C}\right)\end{array}$ & & & \\
\hline & Frit & 1 & 900 & $33.3(\%)$ & Same as & Same as \\
\hline & & 2 & 860 & 33.3 & 1 & in 1 \\
\hline $\begin{array}{c}\text { Con- } \\
\text { stituent }\end{array}$ & & 3 & 750 & 33.3 & & \\
\hline $\begin{array}{l}\text { of ground } \\
\text { coat slip }\end{array}$ & & & Clay 1 & & $5(\%)$ & $7(\%)$ \\
\hline & & & Clay 2 & $5(\%)$ & & \\
\hline & Mill & & Silica & 15 & 15 & 15 \\
\hline & tions & & Borax & 0.3 & 0.3 & 0.3 \\
\hline & & & $\mathrm{NaNO}_{2}$ & 0.1 & 0.1 & 0.1 \\
\hline & & & $\mathrm{H}_{2} \mathrm{O}$ & 40 & 40 & 40 \\
\hline F.F.I. of & lip ( & $\mathrm{nm})$ & & 33 & 33 & 33 \\
\hline $\begin{array}{l}\text { Occupatic } \\
\text { than } 40 \mu\end{array}$ & $\begin{array}{c}\text { ratio } \\
\text { grol }\end{array}$ & of bu & $\begin{array}{l}\text { ubbles larger } \\
\text { coat }(\%)\end{array}$ & 13.8 & 2.9 & 4.2 \\
\hline
\end{tabular}

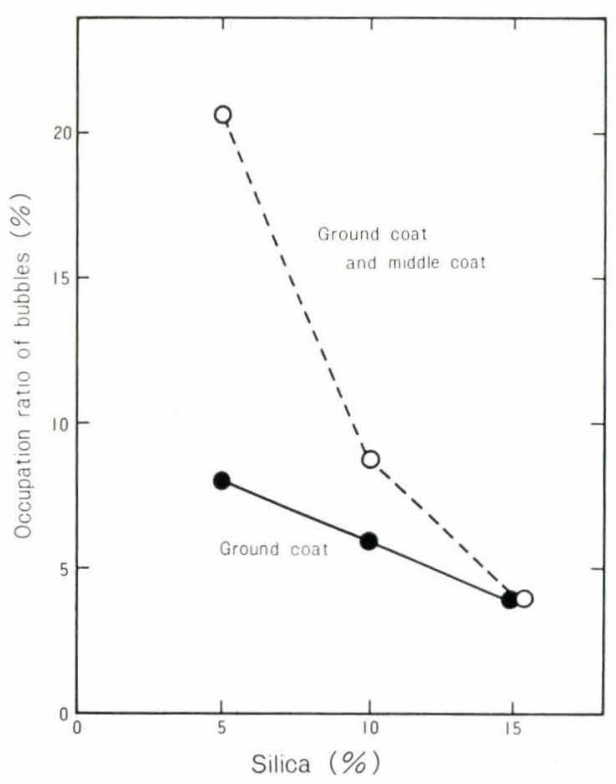

Fig. 7. Influence of silica content on occupation ratio of bubbles larger than $40 \mu \mathrm{m}$ in diameter. 
but excessive silica addition makes slips less workable and may cause hair cracks. The experimental upper limit of silica addition is found to be $15 \%$ from our study.

\section{Conclusions}

Bubble structures in porcelain enamel, especially in the ground coat, are important features in enameling since they determine the usefulness of the enameled wares. It was made clear that large bubbles tend to cause chipping at the sharp corners of an enameled ware and reduce the impact strength of the enamel. Adhesion of the enamel to a base steel depends on the bubble structures but test results are not consistent for various methods. The ball impact test indicates that small bubbles are desirable, while large bubbles are better in the P.E.I. adherence test.

The methods to obtain small bubbles are summarized as follows;

(1) Bubbles are generated by air entrapped at boundaries between frit particles. The distance between the particles should be narrow for small bubbles and this means that small frit particle sizes are better in obtaining small bubbles.
(2) Hard frits make smaller bubbles than soft frits do. Frits can be classified into hard to soft frits by fusion flow index. Silica additions make bubbles small.

(3) Clay as mill additives greatly affects bubble structures not because of the change of fusion flow index but because of the organisms in it.

\section{REFERENCES}

1) B. Walker: Vitreous Enamellers, 17 (1966), 41.

2) C. G. Bergeron: J. Amer. Ceram. Soc., 36 (1953), 373.

3) I. Takahashi, A. Yasuda, K. Ito and N. Ōhashi: Kawasaki Steel Technical Report, 7 (1975), 189.

4) Y. Shiraki: Glaze and Pigments, Gihōdō, Tokyo, (1977), 172.

5) A. Peterson and A. I. Andrews: J. Amer. Cerm. Soc., 28 (1945), 102.

6) A. I. Andrews: Porcelain Enamels, 2nd ed., Garrard Press, Illinois, (1961), 522.

7) ASTM C 313-59 (Reapproved 1972).

8) D. B. Clay and R. M. Jamieson: Ceram. Age, (1967), 32.

9) S. Harada: Kawasaki Steel Technical Report, 5 (1973), 242.

10) R. Gee-Pemberton and B. Walker: Inst. Vitreous. Enamel Bull. 18 (1967), 41. 